\title{
Study of the work and efficiency improvement of combined-cycle gas turbine plants
}

\author{
D I Mendeleev ${ }^{1,2, *}, Y u$ Ya Galitskii ${ }^{1}, G E$ Marin $^{1,2}$ and A R Akhmetshin ${ }^{1}$ \\ ${ }^{1}$ Kazan State Power Engineering University, 420034, Krasnoselskaya St., 51, Kazan, Russian Federation \\ ${ }^{2}$ JSC "Tatenergo" branch "Kazan CHP-2", 420036, Tatsevskaya St., 11, Kazan, Russian Federation
}

\begin{abstract}
The purpose of the paper is to study and analyze the possibility of increasing the power output of a combined-cycle gas turbine (CCGT) unit during the period of positive ambient temperatures. The first task is to analyze the operation of a $110 \mathrm{MW}$ combined-cycle power unit at various ambient temperatures and to obtain alterations in the main CCGT characteristics when the ambient temperature changes. The other task is to study the usage of an absorption refrigeration machine in a CCGT cycle to increase its energy efficiency. Calculations of the thermal scheme of a gas turbine were carried out using mathematical modeling, the steam turbine was calculated based on guidelines. The conducted studies allow to conclude that the use of an absorption refrigeration machine in the cycle of a combined-cycle plant can improve the efficiency of the unit, increasing profits from power generation, and reducing penalties for non-compliance with the load schedule.
\end{abstract}

\section{Introduction}

The problem of obsolescence and physical aging of the power equipment park is very relevant today. Reconstruction and commissioning of new equipment for thermal power plants should be carried out using new technological solutions and new technologies. The energy strategy of the energy sector up to the year 2030 includes commissioning of new natural gas power units of combined-cycle gas turbine plants with capacities of 100, 200, and $450 \mathrm{MW}$. Gas turbine engines are currently widely distributed in combined-cycle power units when modernizing and replacing the equipment of power plants. [1]

The advantages of a CCGT (high efficiency, low cost per unit of installed capacity, short construction time, lower water consumption per unit of generated electricity, compact size, faster start-up), if used in thermal power plants (TPP) modernization or construction of new stations, can be considered as one of the stages of increasing station maneuverability. However, given one of the drawbacks of the CCGT which is seasonal power limitations (maximum performance during winter) and the fact that a reasonable and proper choice of the power installed by the CCGT and its auxiliary equipment is necessary, it makes it difficult to increase station maneuverability only by the CCGT.

Currently, all power units of the CCGTP operate in wholesale electricity markets and capacity markets, where it is necessary to carry out a planned dispatch schedule set by a system operator. In case of deviation from a specified load by an amount exceeding $2 \%$ of the declared maximum on-power but not less than by $1 \mathrm{MW}$ at the end of an hour for more than 4 consecutive hours and when this deviation is not related to the disconnection of the generating equipment, the corresponding decrease in maximum power is recorded for all hours. [2-4]

The purpose of this paper is to study and analyze the possibility to increase the power output of a combined cycle-gas turbine (CCGT) unit during periods of positive ambient temperatures.

\section{Materials and methods}

The article describes an example of CCGTP-220, consisting of two $110 \mathrm{MW}$ units, each of which consists of a PG6111FA type gas-turbine unit (GTU) from "GE Energy" (the main characteristics of the gas turbine installation are presented in Table 1) with a rated power of $77 \mathrm{MW}$, a stationary KT-33/36-7.5/0.12 cogeneration steam turbine with adjustable heating steam extraction, an E-114/16-8.1/0.7-535/218-3.8vv type waste-heat recovery boiler (WHRB) and necessary accessories to them.

Technological constraints on power generation of power plants have a great influence on economic activity of electric power companies. These restrictions are associated with performance deterioration of the main equipment with increase of ambient temperatures. [5-7]. There are several steps that can be taken to remove or alleviate these restrictions.

In articles [8-9], water injection into a gas turbine compressor is considered and results in an increase in power production. This supply of additional working

\footnotetext{
* Corresponding author: dylankn@ya.ru
} 


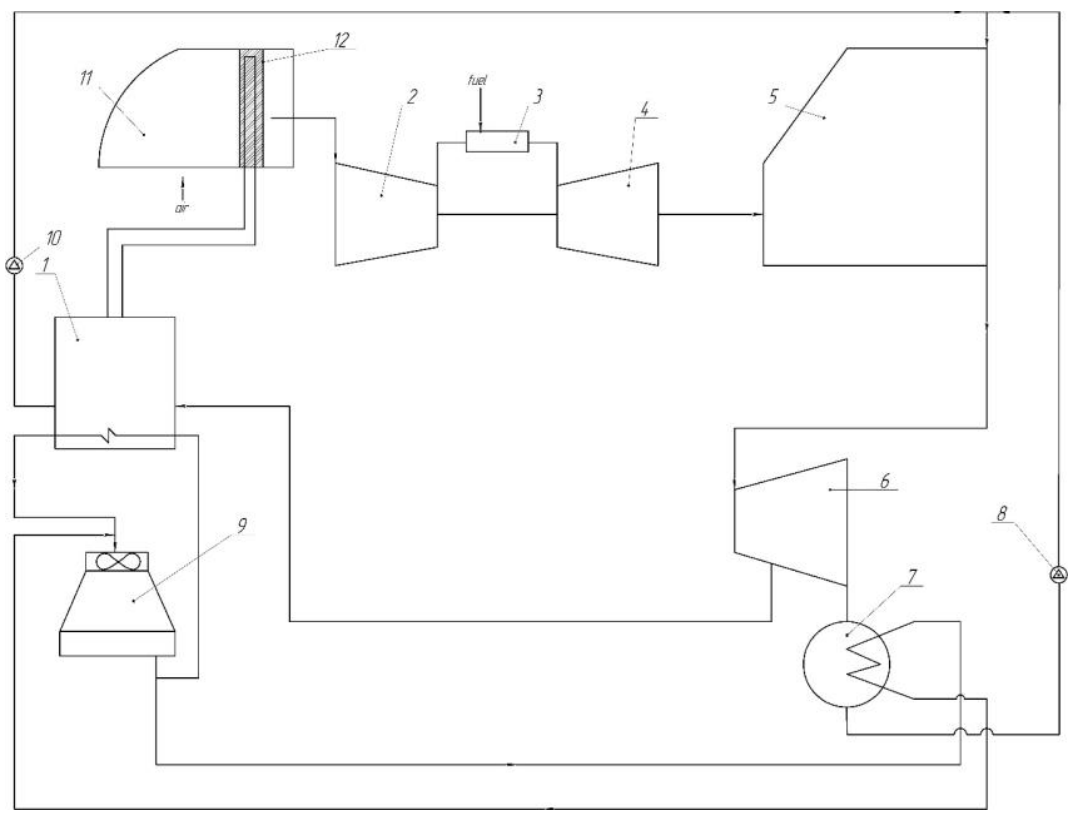

Fig. 2. Connection and operation scheme of the absorption refrigeration machine in the CCGT cycle $(1-$ an absorption refrigeration machine; 2 - a multistage compressor; 3 - a combustion chamber; 4 - a gas turbine; 5 - a waste heat boiler; 6 — a steam turbine; 7 - a capacitor; 8 - a condensate pump; 9 - a fan cooling tower; 10 - a technical water pump; 11 - an Air Filtering and Conditioning System; 12 - a heat exchanger).

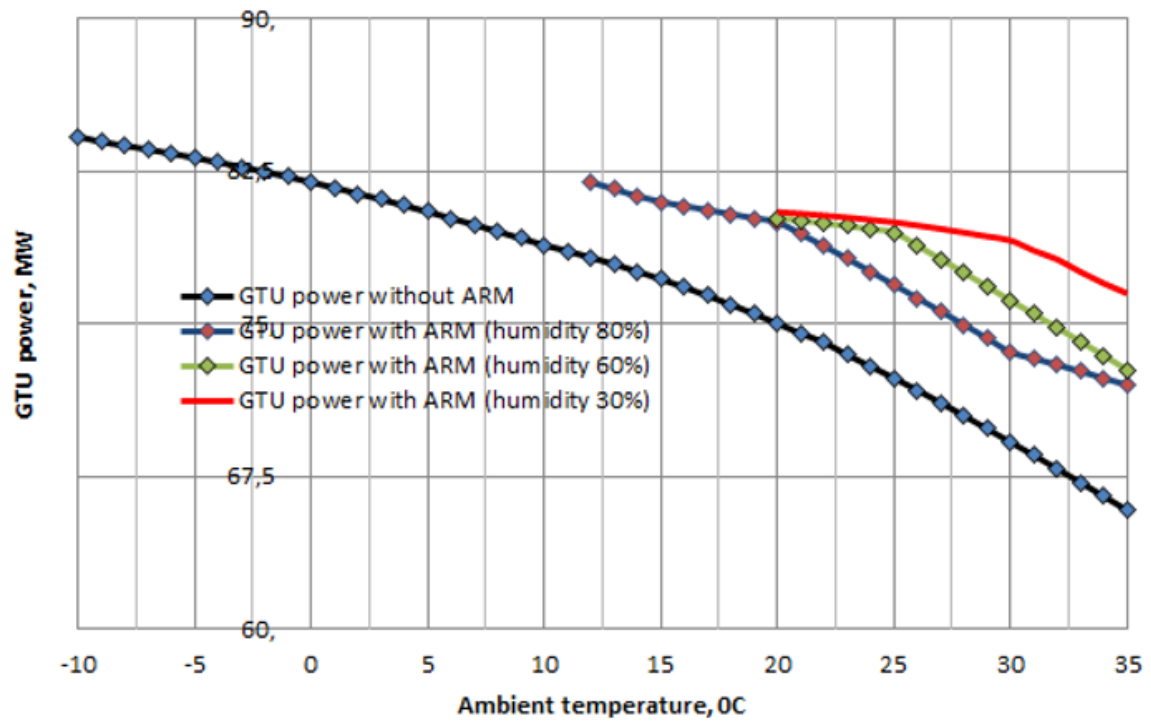

Fig. 3. The dependence of the power of gas turbines on the ambient air temperature without an absorption refrigeration machine and with it at various values of humidity.

generation by the combined-cycle gas turbine plant, it was proposed to apply pre-cooling of air before it enters the compressor. As a source of cold it is proposed to use absorption refrigeration machine. [13-17]

The operational principle of an absorption refrigeration machine is based on certain properties of the refrigerant and absorbent, which provide heat removal, cooling and maintaining the required temperature conditions.

At present, the industry widely uses absorption refrigeration machines to produce cold in an area of positive temperatures for various technological needs. The effectiveness of an ARM depends on parameters of external heat sources, temperature drops in the turther beneticial use tor own needs of the power plant. After leaving the compressor, the air enters the combustion chamber 3 where it is mixed with fuel, after the mixture of hot gases enters the gas turbine. After leaving the gas turbine, exhaust gases enter the waste heat boiler 5 , where the energy of the gases is consumed to produce steam. The steam is sent to the steam turbine 6 with the attached condenser 7 to condense the exhaust steam. The exhaust steam is then reintroduced to the cycle by the pump 8 . Cooling water is supplied to the condenser from the cooling tower 9, designed for heat removal as well as low-potential "waste" thermal energy removal from the ARM, the volume of which is defined as the sum of heat from the heating steam and cooled air. 
The ARM cools ethylene glycol supplied to the AFVS heat exchanger. During such work, energy is expended only on the operation of pumping equipment. In the AFVS, air is prepared at the compressor inlet, filtered from large and small particles.

Two-factor characteristics allow:

1) to determine the optimal mode of operation of the equipment under the terms of economical work;

2) to predict changes in the output parameters of the gas turbine unit depending on the initial values;

3) to determine the boundary conditions of the working range of loads.

As a heating medium for the ARM, steam is used from the output of a steam turbine with a pressure of $0.05 \mathrm{MPa}$, with a flow rate of the order of 10 tons per hour in nominal mode of operation.

The ARM allows to regulate the cooling load necessary for cooling the air in front of the GTU by changing the amount of steam supplied to the ARM by the flow regulator in range from $40-100 \%$ of the nominal load of the GTU. The power expended by the ARM is calculated depending on the values of the temperature of the cooled air under given climatic conditions.

Humidity is one of the important factors affecting the operation of a gas turbine with an ARM. With different humidity levels a different cooling effect is achieved (figure 3).

\section{Conclusion}

An integrated approach has been developed to solve problems of summer power limitation associated with a decrease in the generated power of a gas turbine.

In order to reduce the effect of high temperature of compressible air on the electricity generation, it was proposed to apply pre-cooling of the air before it enters the gas turbine compressor. It is proposed to use an absorption refrigeration machine as a source of cold. The use of an absorption refrigeration machine in the cycle of a gas-steam plant does not imply changes to the design of the main equipment (turbine or gas turbine compressor), thereby minimizing both the costs and the time for modernization.

As a result of the theoretical research, including mathematical modeling and selection of the type of absorption machine with regard to productivity, a flow chart of the installation of an ARM in the production cycle of a combined-cycle plant has been developed.

The operation of the CCP power unit at constant temperatures at the inlet to the gas turbine allows:

1) to work in the summer period under the schedule of loading without penalties;

2) to operate at constant load while increasing the service life and reliability of the equipment;

3) to improve the maneuverability of the unit and reduce the dependence on the outdoor temperature;

4) with an ARM, to generate additional electricity, thereby obtain additional profit.

In this case, it is possible to achieve load values of the GTU that are optimum for operating in the electricity market. With such capacities, the maximum efficiency of the combined-cycle plant and the minimum power consumption of the ARM are achieved when installed in a production cycle to increase the capacity of the GTU.

\section{References}

1. The energy strategy of Russia for the period up to 2030 (approved by the Order of the Government of the Russian Federation No. 1715-p dated November 13, 2009) [Electronic resource], Reference Legal System Consultant Plus.

2. P. Ivanova, E. Grebesh, O. Linkevics, Optimisation of combined cycle gas turbine power plant in intraday market: Riga CHP-2 example, Latvian Journal of Physics and Technical Sciences, 55(1), 15-21 (2018) doi: 10.2478/lpts-2018-0002.

3. Government Decree dated October 24, 2003 N 643 "On the rules of the wholesale electricity market (power) during the transition period" [Electronic resource], Reference Legal System Consultant Plus.

4. D.I. Mendeleev, G.E. Marin, Eds. S.V. Safronov, Factors affecting the ability of the CCGT unit to generate a given power and the fulfillment of a given electrical load curve, Modern technology in the energy sector. All-Russian Specialized Scientific and Practical Conference of Young Specialists, 36-40 (2018)

5. G.L. Hou, L.J. Gong, X.Y. Dai, M.Y. Wang, C.Z. Huang, A Novel Fuzzy Model Predictive Control of a Gas Turbine in the Combined Cycle Unit, Complexity, 18, 6468517 (2018) doi: $10.1155 / 2018 / 6468517$.

6. O. Mohamed, J.H. Wang, A. Khalil, M. Limhabrash, Predictive control strategy of a gas turbine for improvement of combined cycle power plant dynamic performance and efficiency, Springerplus, 7(5), 20 (2016) doi: 10.1186/s40064-016-2679-2.

7. S. Bahrami, A. Chaffari, M. Genrup, M. Thern, Perfomance Comparison between Steam Injected Gas Turbine and Combined Cycle during Frequency Drops, Energies, 8, 7582-7592 (2015) ISSN 1996-1073

8. A.L. Berkovich, V.G. Polishchuk, A.V. Nazarenko, Forcing stationary gas turbines with optimal injection of water into the compressor, St. Petersburg State Polytechnic University Journal of Engineering Science and Technology, 2(219), 3340 (2015)

9. A.A. Kudinov, S.P. Gorlanovm, Improving the efficiency of the gas turbine installation by injecting water vapor into the combustion chamber of the NK-37 engine, Vestnik SGASU. Urban planning and architecture, 1(14), 103-109 (2014)

10. A.B. Shigapov, A.A. Shigapov, Regular exhaust gas heat of GTU in schemes with intermediate air cooling, Proceedings of the higher educational institutions. Energy sector problems, 20-28 (2010)

11. G.E. Marin, D.I. Mendeleev, Summing up various substances to improve the energy characteristics of gas turbines, Modern technology in the energy sector. All-Russian Specialized Scientific and 
Practical Conference of Young Specialists, 41-45 (2018) ISBN 978-5-905858-22-2

12. A. Gonzalez-Diaz, A.M. Alcaraz-Calderon, M.O. Gonzalez-Diaz, A. Mendez-Aranda, M. Lucquiaud, J.M. Gonzalez-Santalo, Effect of the ambient conditions on gas turbine combined cycle power plants with post-combustion $\mathrm{CO} 2$ capture, Energy, 134, 221-233 (2017) doi: 10.1016/j.energy.2017.05.020.

13. F.W. Yu, K.T. Chan, J. Yang, R.K..Y Sit, Cooling effectiveness of mist precooler for improving energy performance of air-cooled chiller, Thermal Science, 22(1), 193-204 (2018) doi: $10.2298 / \mathrm{tsc} 1151112071 \mathrm{y}$.

14. H.F. Zuniga-Puebla, E.C. Vallejo-Coral, J.R.V. Galaz, Thermodynamic analysis of one and two stages absorption chiller powered by a cogeneration plant, Ingenius-Revista De Ciencia Y Tecnologia, 6-7(21), $41-52 \quad$ (2019) doi: 10.17163/ings.n21.2019.04.

15. P. Benrajesh, A.J. Rajan, Design and analysis of a two-stage adsorption air chiller, in 2nd International Conference on Frontiers in Automobile and Mechanical Engineering, 197 (2016) BRISTOL: Iop Publishing Ltd, in IOP Conference Series-Materials Science and Engineering, 2017, doi: 10.1088/1757899x/197/1/012030. [Online]. Available: $<$ Go to ISI $>$ ://WOS:000411055100030

16. L.V. Galimova, Absorption chillers and heat pumps. Textbook, 226 (1997)

17. R. Cozzolino, Thermodynamic Performance Assessment of a Novel Micro-CCHP System Based on a Low Temperature PEMFC Power Unit and a Half-Effect $\mathrm{Li} / \mathrm{Br}$ Absorption Chiller, Energies, 2(11), 21 (2018) doi: 10.3390/en11020315. 